\section{AIDS in Africa: is it a myth?}

SIR - In The Sunday Times of 21 March 1993 in an article entitled "Epidemic of AIDS in Africa 'a tragic myth" the following appears:

A British expert puzzled by the disparity between apocalyptic warnings about the spread of AIDS in Africa and her own observations is Professor Beverley Griffin

For the past seven years she has received blood samples of hundreds of children in Malawi. The proportion that are HIVpositive has remained unchanged, at $1-2 \%$. This casts doubt, she feels, on claims made elsewhere that Malawi is in the grip of an HIV epidemic, with about a fifth of its population infected.

Our letter in response to this article (Nature 366; 716; 1993) argued that such prevalences amongst children reflect a high prevalence among adults. We fail to see how commenting on data published in a national newspaper is a breach of ethics and etiquette as Griffin claims (Nature 367, 212; 1994). We suggest that Griffin should take up any grievances with the author of the article in The Sunday Times.

We also fail to see how the prevalences quoted by Griffin from our paper (R. M. Anderson et al. Nature 352, 582-589; 1991) illuminate the debate. We clearly point out that the populations in question were urban, and repeat this in our letter responding to The Sunday Times article. Geoff Garnett

\section{Roy Anderson}

University of Oxford,

Department of Zoology,

Infectious Disease Epidemiology Unit,

Oxford OX1 3PS, UK

\section{When to speak}

SIR - In your leading article (Nature 367, 301 ; 1993) about the prison sentences served by Dr Michel Garretta and Professor Jean-Pierre Allain, you ask what a public official is to do if he knows official policy to be dangerous. "To broadcast his disquiet to the public, or to attempt to work within the bureaucracy that employs him?" In fact, Allain did give an interview on his fears to the French newspaper Le Matin, but it was not published. His wife, the immunologist Dr Helen Lee, tried to warn the public at a meeting of 200 leading haematologists and other experts and was officially reprimanded for doing so. As I understand it, a recent ruling by our own government expressly forbid civil servants to take such a step on pain of disciplinary action.

\section{F. Perutz}

MRC Laboratory of Molecular Biology,

Hills Road, Cambridge CB2 2QH, UK

\section{Biased view}

SIR - Our companies publish three competing bibliographic software products: Reference Manager, EndNote and ProCite. On 11 November, Nature published a review of another bibliographic software package (Nature 366, 183-84; 1993). The article was written by the producers of the product being reviewed and they compared their product to ours. We feel that it is unethical and misleading to allow authors to review their own software. As the article appeared in your Product Review section, readers may perceive it as an unbiased review, which it is not. We appreciate accurate critical reviews that give the reader a basis on which to choose a product, but a 'review' by the author of a work can only be biased.

\section{Victor Rosenberg}

Personal Bibliographic Software, Inc.,

POBox 4250, Ann Arbor,

Michigan 48106-4250, USA

Richard Niles

Niles \& Associates, Inc.,

2000 Hearst Avenue, Suite 200,

Berkeley, California 94709, USA

\section{Earl B. Beutler}

Research Information Systems,

2355 Camino Vida Roble,

Carlsbad, California 92009, USA

\section{Nuclear Sweden}

SIR - In 1980, the Swedish population decided in a referendum to phase out nuclear power by 2010 . This choice hinged on being given the time to develop suitable alternatives. Today, the Swedish government seems to be hesitating about fulfilling its obligation, and nuclear plant operators and organizations such as the Swedish Royal Academy of Engineering Sciences (IVA) are openly advocating that the referendum decision be reversed.

The argument is that time has shown that, despite huge efforts, it has not been possible to provide a viable alternative to nuclear power ${ }^{1}$. Although the Swedish government has spent quite large sums on exploring alternatives, much of the money was spent on paper studies, including a stream of alternative energy plans. Industrial efforts to develop alternatives have not been successful in Sweden. Yet in neighbouring Denmark, a wind turbine industry has grown into a billion-kroner export business. And solar thermal collectors seem to be more abundant in most other European countries than in Sweden.

Swedish government policy has ensured that no alternatives were given a chance. No environmental tax has ever been levied on cheap Swedish electricity, and no market for wind power, for example, has been created. In Denmark, a 30 per cent subsidy helped the wind industry to get started. This subsidy was given to customers, and a requirement that the full investment should be recovered in less than 8 years prevented manufacturers from including the subsidy in their pricing. Subsequently, as wind energy became increasingly viable, the subsidy was reduced to 20 per cent then to 10 per cent, and then abandoned.

Sweden uses all its hydro and nuclear power generating capacity, and has to import electricity every time the nuclear plants are closed with some problem (which recently happened to all of them at the same time). Sweden has no alternative to nuclear power because it deliberately chose a policy barring the development of such alternatives.

Bent Sørensen

Roskilde University, Institute 2,

PO Box 260, DK-4000 Roskilde, Denmark

1. Engström, G. Energy for coming Generations. In Proc. 5th Int. Energy Conference, 1993, Seoul, South Korea (in the press)

\section{Let's have a word}

SIR - Work has recently begun at Oxford University Press on a comprehensive revision of the Oxford English Dictionary $(O E D)$, to be published in 2005 .

The published literature of science is so vast that it is impossible to scan all of it for relevant information. As part of the process of revising and updating the dictionary, we should like scientists who have relevant information to contact us.

As an example, Professor Joshua Lederberg e-mailed us about the omission of C. S. Peirce's philosophical sense of 'abduction', not recorded in the $O E D$, and his own coinage of the words 'eugram' and 'eugraphy'.

Information of particular interest would include: the coinages of particular scientific words, where this information is not already given; factual errors in definitions; scientific words and meanings not in the $O E D$ (second edition, 1989); and referenced examples of words and meanings that predate the earliest quotation given in the $O E D$.

The last category is especially useful: the $O E D$ is a historical dictionary that aims to trace every word and meaning back to its earliest known use in the English language, as well as giving references to the coinages of foreign precursors of English words. Such first uses can be difficult to track down; for example, we have been unable to find any use of the word 'multiplicatively' earlier than 1914 , even though it is in Funk and Wagnalls' Standard Dictionary of 1895.

\section{A. M. Hughes}

(Chief Science Editor)

Oxford English Dictionary,

Oxford University Press,

Walton Street, Oxford OX2 6DP, UK

e-mail: ahughes@oup.co.uk. 